well, that sex may be determined by a quantitative effect, with possibly a threshold mechanism, brought about "by the agency of relatively large chromosomal regions or even whole chromosomes".

I find that these two necessarily sketchy and specilative chapters, at the end of an otherwise factual book, are useful because they aim to point out important gaps of knowledgo and areas where hypotheses abound and where their testing is particularly topical. P. E. Polani

\section{FURTHER DEVELOPMENTS}

\section{Advances in Morphogenesis}

Vol. 6. Edited by M. Abercrombie and Jean Brachet. Pp. viii +33l. (New York: Academic Press, Inc.; London: Academic Press, Inc. (London), Ltd., 1967.) $120 s$.

Whenever I pick up a book with a title like Advances in Morphogenesis, I hope to find that at last someone has found some sort of key to the problem of the link between biochemical and morphological structure. Perhaps I am made unduly optimistic by the remarkable advances in our understanding of the nature and functioning of the genetic code in bacteria and viruses characteristic of recent years. Needless to say, I am always somewhat disappointed to find that "morphogenesis" is usually taken to mean the development of biochemical diversity, or at most a superficial account of cellular differentiation.

With this limitation in mind, however, Abercrombic and Brachet's sixth volume of Advances in Morphogenesis is a worth-while addition to the library of anyone interested, not necessarily just in embryology in the classical sense, but in the genetics, biochemistry and physiology of developing animals and plants. Indeed, only two articles are concerned primarily with morphogenesis-one by Michael Locke on pattern development in the insect integument, and one by Allsop on heteroblastic devclopment in plants. Both are useful and detailed roviews, although the pitiable state of our understanding is well illustrated by a quotation from each author: "There is a continued need to recognize that the terms used in this description may have no reality in the phenomena being studied. We can proceed no further until somo structural, physiological, or biochemical correlation has been made' (Locke, page 82); or "There is also no conclusive evidence that physiological ageing is determined by any intrinsic ageing of the mature tissues of the plant. . . . A plausible explanation of these changes invokes a regulatory effect of the intracellular environment on gene activity. But it is not even certain that changes in gene activity are necessary" (Allsop).

Astaurov's paper on cytogenetic mechanisms in silkworms is more an assessment of the relative roles of nucleus and cytoplasm in development, and various modes of parthenogenesis, than a genuine attack on problems of morphogenesis. Interesting as it is, I feel that it could have been somewhat compressed without loss. It contains, however, detailed descriptions of methods which could be useful to the experimenter.

Wilt's article on embryonic haemoglobin synthesis, and Wischnitzer's on the ultrastructure of the amphibian egg, are neither of them strictly concerned with morphogenesis. Both are very adequate reviews, and the latter is beautifully illustrated; but whether this volume is really the proper place for their publication is perhaps doubtful.

"The Biology of Teratomas", by Leroy Stevens, interested me particularly, largely because it directs attention to what was to me an unusual realm of embryological investigation. That primordial (male) germ cells may be able to give rise to alrnost all kinds of tissue in a teratoma, even if in a disorganized way, must surely have sig. nificance in relation to the ordered development of the normal embryo.

Finally, L. Gallien's account of sexual organogenesis, in both invertebrates and vertebrates, is an admirable summary of advances in our knowledge of sex-determination, especially in relation to endocrine control in invertebrates. Whether the clarity of this article derives from the original French or in part from the excellent translation, it leaves a lasting impression of how good a review article can be.

MIChaEL BegG

\section{GEOLOGY OF FOLDS}

\section{Structural Geology of Folded Rocks}

(Rand McNally Geology Series.) By E. H. Timothy Whitten. Pp. xiv +663 . (Chicago: Rand MeNally and Company, 1966.) $\$ 10.50$.

THE crust of the Earth has had a complex deformation history as a result of past orogenic disturbances. Great advances have been made in recent years in the understanding of the fracture patterns and folded forms taken up by stratified rocks during these deformations. Professor Whitten's book describes the morphology of folded rocks and structures associated with folds. It aims at guiding the reader through the modern literature, mueh of which is scattered through a number of specialist journals, and synthesizing these data.

I'he appearance of the book is immediately attractive, and departs radically from many traditionally oriented texts on structural geology now available. The production is excellent and the publishers are to be congratulated on the way that they have reproduced the many figures, maps and photographs. The text, however, is disappointing; the writing is verbose and repetitive, and several chapters are heavily weighed down with jargon. Although Professor Whitten has been industrious in his incorporation of the results of others, in his compendium of data there is often an unfortunate lack of critical discussion as to their significance. This book purports to be a synthesis; but a collection of data must be integrated into some logical system before it deserves this description. Rarely does the author arrive at firm conclusions or offer to pass on to the reader his own experience in any personal commitment. In discussions on controversial matters (for example, the significance of foliation, page 263) he gives no clear summarios of the various alternative working hypotheses that may explain the facts.

The book is profusely illustrated; of the 485 figures more than 80 per cent have been published before. It is mosi useful to have all these illustrations together in one book, but it is a pity that their integration into the text is sometimes so poor. For example, although Professor. Whitten has set out to base his account of folds on actually described field relations, there seems little justification for reproducing eighty-four small field sketches of folds (Figs. 182, 183 and 184) when they are discussed in only two sentences in the text. Professor Whitten's original contributions to the illustrative material are mostly confined to stereographic and equal-area-projections of geometrical forms, and some simple and rather unrealistic maps showing the geology of hypothetical regions. Where original diagrams have been included in the sections on slip folds (Figs. 110 and 112) and superposed folds (Figs. 302 and 303) the presentation of the complex three dimensional geometrical properties is so ill conceived that I seriously doubt their usefulness.

Griffiths has claimed that "progress in science can generally be measured by the degree in which the subjeet is pervaded by mathematics". Professor Whitten supports this assertion, yet he provides no summary of the analytical methods which have been used during the past 